\title{
Contratación pública y derechos humanos
}

JoAquín TORnOS MAS

\section{RESUMEN}

El presente trabajo busca dar cuenta de cómo en los últimos años la contratación pública se ha concebido como un instrumento en manos de los poderes contratantes, que les permite alcanzar unos fines complementarios a los de dotarse de obras, bienes y servicios. Es lo que se conoce como contratación estratégica. Uno de estos fines debe ser la protección y defensa de los derechos humanos, fin esencial en todo Estado democrático. Por ello, se trata de imponer en las diversas fases de la contratación mecanismos que aseguren el logro de este fin complementario. Junto a la reflexión general sobre esta nueva concepción de la contratación estratégica, se da cuenta de dos recientes experiencias en las que se concretan las medidas a adoptar en procesos de contratación.

Palabras clave: contratación estratégica, derechos humanos, preparación y adjudicación del contrato, ejecución del contrato, resolución del contrato, responsabilidad corporativa, supervisión de la ejecución del contrato.

\section{Public Procurement and Human Rights}

\author{
ABSTRACT
}

The present work tries to give an account of how, in recent years, public procurement has been conceived as an instrument in the hands of the contracting powers that allows them to achieve complementary purposes to those of equipping themselves with works, goods and services. This is known as strategic contracting. One of these purposes must be the protection and defense of

1 Profesor de la Universidad de Barcelona, Barcelona, España. Doctor en Derecho de la Universidad de Bolonia, Bolonia, Italia. Correo-e: jtornos@ub.edu. Enlace ORCID: https:// orcid.org/0000-0001-9690-5194. Fecha de recepción: 2 de marzo de 2020. Fecha de modificación: 5 de abril de 2020. Fecha de aceptación: 2 de mayo de 2020. Para citar el artículo: Tornos MAS, JoaQuín, "Contratación pública y derechos humanos", Revista digital de Derecho Administrativo, Universidad Externado de Colombia, n. ${ }^{\circ} 24,2020$, pp. 11-41. DOI: https://doi.org/10.18601/21452946.n24.02. 
human rights, an essential goal in any democratic State. Therefore, it is about imposing mechanisms in the various phases of contracting that ensure the achievement of this complementary purpose. Along with the general reflection on this new concept of strategic contracting, two recent experiences are highlighted, in which the measures to be adopted in contracting processes are specified.

Keywords: Strategic Contracting, Human Rights, Preparation and Contract Awarding, Contract Execution, Contract Termination, Corporate Responsibility, Contract Execution Supervision.

\section{INTRODUCCIÓN. LA CONTRATACIÓN ESTRATÉGICA}

La contratación pública, definida por la Unión Europea como el proceso a través del cual las autoridades públicas compran obras o servicios a las empresas utilizando dinero público, se ha convertido en los últimos años en un instrumento fundamental para la promoción de la responsabilidad social empresarial. Teniendo en cuenta la importancia de la contratación pública en la actividad económica general (en España representa el 18,5 del PIB total), es indudable su capacidad para fomentar la transformación hacia un mundo más sostenible y social, en el que los derechos humanos estén garantizados.

Si prestamos atención a la situación en Europa, comprobamos que las autoridades de la Unión Europea invierten cada año alrededor de un 14\% del PIB total en la compra de obras, servicios y suministros. La contratación pública es uno de los pilares de la Estrategia 2000 de la Unión Europea. La Estrategia marco ha reconocido a la contratación como una herramienta básica para conseguir un crecimiento sostenible e integrador, garantizando al mismo tiempo un uso eficiente y racional de los fondos públicos. Como dice la Directiva 2014/24/ UE, "es de capital importancia aprovechar plenamente las posibilidades que ofrece la contratación pública para conseguir los objetivos de la Estrategia Europa $2000^{\prime \prime 2}$.

2 En este mismo sentido, la Oficina del Alto Comisionado de Naciones Unidas para los Derechos Humanos, en la Cuarta Consulta Regional sobre Empresas y Derechos Humanos para América Latina y el Caribe en Santiago de Chile (CEPAL), el 3 y 4 de septiembre de 2019, se pronunció en los términos siguientes: "Los Principios Rectores de las Naciones Unidas sobre las Empresas y los Derechos Humanos dejan en claro que el deber de los Estados de proteger los derechos humanos se extiende a sus actividades de compra. Además, la Agenda 2030 para el Desarrollo Sostenible ha establecido nuevos objetivos en la contratación pública, para impulsar la producción y el consumo sostenibles y el desarrollo de economías más inclusivas: el Objetivo de Desarrollo Sostenible (ODS) 12.7 llama a todos los países a 'Promover prácticas de adquisición pública que sean sostenibles, de conformidad con las políticas y prioridades nacionales'. Paralelamente, importantes actores mundiales, incluidos el G7, la OCDE, la UE y la OIT, están promoviendo un enfoque renovado en 'cadenas de valor mundiales responsables' como clave para un crecimiento 
En esta misma línea se pronunció el Congreso de los Diputados de España, mediante el Informe de la Subcomisión Parlamentaria para promover la responsabilidad social de las empresas en el año 2006, estableciendo que "la compra y la contratación públicas han de ser herramientas claras para el impulso de la responsabilidad empresarial, y han de mandar señales al mercado en el sentido de que las empresas que ofrezcan a la sociedad un valor adicional en materia ambiental y/o social serán reconocidas y premiadas".

De acuerdo con estas nuevas ideas, una de las novedades más importantes de la nueva ley española en materia de contratación pública, la Ley 9/2017 del 8 de noviembre de contratos del sector público, por la que se trasponen al ordenamiento español las directivas comunitarias 2014/23/UE y 2014/24/UE del 26 de febrero, es que superó una visión de la contratación pública centrada únicamente en los aspectos económicos de los contratos (lograr los mejores precios en la adjudicación y una ejecución eficaz posterior), para incorporar otros fines. Para la nueva ley, la contratación debe tener otros objetivos de interés general complementarios de los anteriores, como son el fomento de la innovación, la protección medio ambiental, o la política social o laboral. Es lo que se conoce como la consideración de la función estratégica de la contratación ${ }^{3}$. De este modo se pretende que, en España, la contratación pública pase

sostenible e inclusivo, con un fuerte énfasis en la contribución del sector privado, a través de 'conducta empresarial responsable" y la agenda de trabajo decente, para lograr este objetivo".

Véanse José María Gimeno FeLIu, El nuevo paquete legislativo comunitario sobre contratación pública. De la burocracia a la estrategia. El contrato público como berramienta del liderazgo institucional de los poderes públicos, Cizur Menor: Thomson - Aranzadi, 2014; y en particular, del mismo autor, "Las condiciones sociales en la contratación pública: posibilidades y límites", Anuario de Gobierno Local, n. ${ }^{\circ}$ 1, 2017. Véanse también María BurZaCO, "Contrataciones públicas socialmente responsables: la necesidad de reconsiderar el potencial de la contratación pública en la consecución de objetivos sociales", A CIRIEC - Revista de Economía Pública, Social y Cooperativa, n.o 86, 2016, pp. 281-310; Miguel Ángel Bernal Blay, "Hacia una contratación pública socialmente responsable: las oportunidades de la Ley 30/2007 de 30 de octubre de contratos del sector público", en José María Gimeno Feliu (ed.), El derecho de los contratos del sector público, Monografías de la Revista Aragonesa de Derecho Público, n. ${ }^{\circ}$ X. Zaragoza: 2008, pp. 211-252; IsABel Gallego CórCOles, "La integración de cláusulas sociales, ambientales y de innovación en la contratación pública", Documentación Administrativa, nueva época, n. ${ }^{\circ}$ 4, enerodiciembre de 2017; Humberto Gosálbez PequeÑo, "¿Cláusulas sociales en la selección de los contratistas de las administraciones públicas españoles?", Justicia Administrativa, n. ${ }^{\circ} 20$, 2003, pp. 27-67; Santiago Lesmes Zabalegui y Leire Álvarez de Eulate, Guía de contratación pública socialmente responsable, Bilbao: REAs Euskadi, 2014; José María Martínez FernándeZ, "Avanzando en contratación socialmente responsable: de la recomendación a la obligaciones", A Observatorio de Contratación Pública, 2015; Teresa Medina Arnálz, "El destino de las cláusulas sociales en la contratación pública", en José María Gimeno Feliu (dir.), Observatorio de los contratos públicos, Cizur Menor: Thomson-Aranzadi, 2019, pp. 253-275; Juan José Pernas García (coord.), Contratación pública estratégica, Cizur Menor: Aranzadi, 2013; Francisco Pleite Guadamillas. "Incorporación de cláusulas de contenido social, laboral y medio ambiental en los pliegos que rigen las licitaciones de los contratos", A Contratación 
a ser un potente instrumento en manos de los poderes públicos para alcanzar diversos fines generales.

Una clara manifestación de esta nueva comprensión de la contratación pública es la aprobación del Plan para el Impulso de la Contratación Pública Socialmente Responsable por la Orden PCI/566/2019 del 21 de mayo. En la exposición de motivos del citado Plan se afirma que

A través de la "contratación pública estratégica socialmente responsable", las autoridades públicas pueden promover oportunidades de empleo, trabajos dignos, inclusión social, accesibilidad, diseño para todos, comercio justo, el cumplimiento de los derechos laborales y sociales de los trabajadores, la más amplia aplicación de las normas sociales, así como compromisos voluntarios más exigentes en el ámbito de la responsabilidad social de las empresas. Estas actuaciones permiten influir en el mercado e incentivar a las empresas a desarrollar una gestión socialmente responsable, por una parte, de manera directa mediante los bienes y servicios concretos que se adquieren, e, igualmente, por vía indirecta a través del ejemplo de las Administraciones públicas. Todo ello permite impulsar el avance progresivo de la sociedad por la senda del desarrollo sostenible e integrador.

\section{LA PROTECCIÓN JURÍDICA DE LOS DERECHOS HUMANOS. PLANTEAMIENTO GENERAL}

Dentro de estos fines estratégicos de la contratación pública se hace referencia a los fines ambientales y sociales. Por el contrario, la realidad es que la inclusión en los procedimientos de contratación pública de consideraciones sobre los derechos humanos no ha sido frecuente. La legislación sobre contratación pública no ha hecho referencia a esta finalidad y, por otro lado, la exigibilidad del respeto de los derechos humanos por parte de las empresas aún tiene una regulación poco precisa, y las directrices en este sentido están muchas veces contenidas en normas de soft law, actuando más como recomendaciones y propuestas de actuación que como norma prescriptivas y vinculantes. Pero creemos que siendo los derechos humanos el pilar sobre el que se sostiene la vida colectiva dentro de un Estado, y siendo la contratación pública un factor de gasto público de enorme magnitud, deben ponerse en conexión ambas instituciones. Como se ha dicho,

los conceptos que integran el título de este artículo - derechos humanos y contratación pública- pueden parecer un desafío a la realidad, sin embargo, son un complemento perfecto pues a modo de concurso medial, como hablamos los penalistas, la contratación pública será el medio para garantizar los derechos humanos en 
nuestra sociedad. En definitiva, se trata de humanizar a la Administración pública en su actividad económica ${ }^{4}$.

Si se pretende llevar la promoción y defensa de los derechos humanos a la contratación pública no puede olvidarse la singularidad de estos derechos. En este sentido, podemos partir de la definición del Alto Comisionado de las Naciones Unidas para los Derechos Humanos (ACNUDH), según la cual

los derechos humanos son derechos inherentes a todos los seres humanos, sin ninguna distinción de nacionalidad, lugar de residencia, sexo, origen nacional o étnico, color, religión, lengua o cualquier otra condición. Todos tenemos los mismos derechos humanos, sin ninguna discriminación. Son derechos interrelacionados, interdependientes e indivisibles.

Estos derechos, debe reconocerse, tienen un marco jurídico e institucional complejo, en el que se incardinan niveles de decisión diferentes -internacional, europeo, nacional y subnacional-, así como instituciones y organizaciones también diversas para su garantía y protección ${ }^{5}$.

Desde la creación de la Organización de las Naciones Unidas en San Francisco (Estados Unidos) en 1945, el derecho internacional de los derechos humanos ha estado en constante evolución, ciertamente determinado por los condicionantes históricos, políticos e ideológicos de cada momento.

Y si al principio esta rama del derecho regulaba exclusivamente las relaciones entre los Estados soberanos, estos han visto cómo se ha ido limitando su soberanía y se han ido incorporando a las relaciones internacionales nuevos actores no estatales, cuyo papel en la esfera internacional no cesa de crecer. Se trata especialmente de las organizaciones internacionales - no solo las $\mathrm{Na}$ ciones Unidas, sino también organizaciones regionales como el Consejo de Europa y la Unión Europea, y sus homólogos en América, África, el mundo árabe o Asia, la Organización para la Cooperación y el Desarrollo Económicos (OCDE), etc.-, así como la ciudadanía, sea a nivel individual o a través de organizaciones no gubernamentales (ONG) y de la sociedad civil (OSC). También el

4 Pilar Llop, "Derechos humanos y contratación pública", Confilegal, 6 de octubre de 2015. Disponible en línea: https://confilegal.com/20151006-derechos-humanos-y-contratacionpublica/. Véanse también Margarida Camós y María Teresa Vadrí, La posible inclusión de criterios de paz y de derechos bumanos en la contratación pública. Materiales de Paz y Derechos Humanos, Barcelona: Oficina de Promoción de la Paz y de los Derechos Humanos de la Generalidad de Cataluña, 2010; Olga Martín Ortega y Opi Outwhite, "Empresas, derechos humanos y contratación", en Víctor Messeguer Sánchez (dir.), Empresas, derechos bumanos y RSC, Cizur Menor: Thomson Reuters, 2016.

5 El tratamiento de esta cuestión la tomamos del trabajo JOAQUín TORNOS, AgusTí FERNÁNDEZ de Losada, Anna Calvete y Juan Ambrós, Guía para la protección y la promoción de los derechos bumanos en la contratación pública, Barcelona: Creative Commons, 2017. 
sector privado, donde los sindicatos han tenido un papel preponderante como organizaciones de relevancia institucional e interés general, está adquiriendo un papel cada vez más relevante como actor global, aunque su subjetividad internacional todavía es limitada. Y es que sus actuaciones pueden tener un impacto enorme, tanto positivo como negativo, en la defensa y promoción de los derechos humanos a nivel internacional.

Esta ampliación de los actores con competencias y capacidad de influencia en el ámbito internacional se ha visto acompañada de un cambio ideológico en la forma de concebir los derechos humanos, lo que se materializa en la doctrina de la eficacia horizontal de los derechos humanos (o Drittwirkung), en virtud de la cual los derechos humanos dejan de ser solo una garantía para los ciudadanos ante las actuaciones de los Estados (entendiéndose por Estado las Administraciones públicas de cualquier nivel territorial), para determinar también las relaciones jurídicas entre particulares (sean empresas, sindicatos, la ciudadanía a nivel individual o colectivo, las universidades y los centros de investigación, las ONG, etc.).

Es decir, que los sujetos privados, en las relaciones entre ellos, también tienen la obligación de respetar los derechos humanos. Así, los convenios internacionales de la OIT, la Carta Social Europea y otros acuerdos internacionales, con un alto nivel de garantía y eficacia jurídica, también afectan de manera clara la actuación de las empresas.

Dentro de esta reflexión general queremos destacar que, si bien son pocas las obligaciones jurídicas impuestas directamente por el derecho internacional a los actores no estatales, son los Estados, a través de su derecho interno, los que tienen esta potestad (o este deber de protección y garantía, como establece la sentencia del Tribunal Europeo de Derechos Humanos del 23 de septiembre de 2010). Y por ello cobra todo su valor la reflexión sobre el papel de los Estados en la configuración y ejecución de la contratación pública.

A nivel internacional, la mayor parte de las directrices dirigidas al sector privado se han visto canalizadas a través de instrumentos de soft law, no vinculantes, sin que el seguimiento de las actuaciones de este sector pueda dar lugar a reparaciones por incumplimientos jurídicos. Sin embargo, estos principios, las nuevas iniciativas como el Pacto Mundial sobre la Responsabilidad Social de las Empresas (o Global Compact), las diferentes declaraciones de la OIT o los libros verdes y las comunicaciones de la Comisión Europea en este sentido son un estándar internacional con una influencia reconocida $y$, por consiguiente, un impacto potencial muy importante.

El papel preponderante de los Estados en la defensa de los derechos humanos es evidente, pero también debe destacarse la importancia que tienen las empresas en la protección de dichos derechos si nos atenemos al enfoque basado en los derechos humanos que las Naciones Unidas pregonan desde hace unos lustros. Este enfoque pretende implicar a todos los actores de la sociedad, tanto públicos como privados, en la consecución de los derechos 
humanos partiendo de la base de que todos ellos, en mayor o menor medida y de acuerdo con sus competencias y capacidades, pueden actuar, y deben hacerlo, a través de la protección, el respeto o la realización de los derechos humanos.

Así, en el marco de las Naciones Unidas, el representante especial de derechos humanos y empresas transnacionales y otras empresas comerciales, John Ruggie, propuso en 2008 el marco "Proteger, Respetar y Remediar", con el fin de establecer ámbitos de responsabilidad y actuación diferentes para los Estados y las empresas. Esto, para garantizar que las actuaciones de estas últimas no vayan en detrimento de los derechos humanos, sea eliminando o al menos mitigando los efectos negativos, así como proporcionando remedios efectivos a las víctimas en caso de que se produzcan. Este documento incluía un listado de derechos que pueden verse afectados por la actividad empresarial basándose en un estudio previo de 320 casos de presuntos abusos de derechos humanos, listado que no es, en ningún caso, exclusivo ni limitativo. De este documento surgieron los principios rectores sobre las empresas y los derechos humanos (2011), que incluyen recomendaciones concretas y prácticas para la implementación de los principios, consolidando los reclamos del Pacto Mundial. El listado de derechos que pueden verse afectados por la actividad empresarial, tal como lo planteaba Ruggie, es el siguiente:

- Derechos laborales: a) libertad de asociación, b) derecho de organizar y participar en negociaciones colectivas ${ }_{i}$ c) derecho a la no discriminación ${ }_{i}$ d) abolición de la esclavitud y el trabajo forzoso ${ }_{i}$ e) abolición del trabajo infantil ${ }_{i}$ f) derecho al trabajo $;$ g) derecho al salario igual por trabajo igual ${ }_{i}$ h) derecho a la igualdad en el trabajo $i$ i) derecho a una remuneración justa y digna $;$ j) derecho a un entorno laboral seguro; $\mathrm{y}$ k) derecho al descanso y al ocio.

- Otros derechos: a) derecho a la vida, la libertad y la seguridad de la persona; y protección frente a la tortura o el trato cruel, inhumano o degradante ${ }_{i}$ ) reconocimiento y protección iguales ante la ley; c) derecho a un juicio justo; d) derecho a la libre determinación ${ }_{i}$ e) libertad de movimiento ${ }_{i}$ f) derecho de reunión pacífica, g) derecho a contraer matrimonio y formar una familia, ${ }_{i}$ ) libertad de pensamiento, conciencia y religión $n_{i}$ i) derecho a sostener opiniones y a la libertad de información y expresión ${ }_{i} \mathrm{j}$ ) derecho a la vida política ${ }_{i} \mathrm{k}$ ) derecho a la intimidad ${ }_{i}$ ) derecho a un nivel de vida adecuado (en particular, alimentación, vestido y vivienda) $; \mathrm{m}$ ) derecho a la salud física y mental, y acceso a servicios médicos; $n$ ) derecho a la educación, o) derecho a participar en la vida cultural, en los beneficios del progreso científico y en la protección de los intereses de los autores; y p) derecho a la seguridad social.

Pues bien, dentro del citado documento, dos de los principios rectores sobre las empresas y los derechos humanos hacen énfasis en el claro vínculo entre contratación pública y derechos humanos:

- Principio rector 5: "Los Estados deben ejercer una supervisión adecuada a fin de cumplir con sus obligaciones internacionales de derechos humanos cuando contratan los servicios de empresas, o promulgan leyes con este fin, 
que puedan tener un impacto sobre el disfrute de los derechos humanos", dado que "los Estados no renuncian a sus obligaciones internacionales de derechos humanos para privatizar la prestación de servicios con un posible impacto sobre el disfrute de los derechos humanos".

- Principio rector 6: "Los Estados deben promover el respeto de los derechos humanos por parte de las empresas con las que llevan a cabo transacciones comerciales", en el que se apunta especialmente que los Estados tienen "oportunidades excepcionales -individual y colectivamente- de promover la concienciación y el respeto de los derechos humanos entre las empresas, en particular al estipular los términos de los contratos, otorgando la atención debida a las obligaciones del Estado dimanantes de la legislación nacional e internacional".

Por su parte, el Informe de la Comisión de Asuntos Exteriores del Parlamento Europeo, del 19 de julio de 2016, sobre la responsabilidad de las empresas por violaciones graves de los derechos humanos en terceros países, afirma:

Se observa que la globalización y la internacionalización crecientes de las actividades empresariales y las cadenas de suministros aumenta la importancia de la funciones que desempeñan las empresas en el referente a velar por el respeto de los derechos humanos y crea una situación en la que los estándares, las normas y la cooperación internacionales son fundamentales para evitar violaciones de los derechos humanos en terceros países; manifiesta su profunda preocupación por las violaciones de los derechos humanos cometidas en terceros países, también como consecuencia de algunas decisiones en materia de gestión tomadas por empresas y sociedades mercantiles así como por particulares, agentes no estatales y agentes estatales; recuerda a los agentes empresariales que en operaciones a escala mundial tienen la responsabilidad de respetar los derechos humanos, con independencia de donde se encuentren sus usuarios y de si el Estado de acogida cumple o no sus obligaciones en materia de derechos humanos. Reitera la urgente necesidad de actuar de manera continuada, eficaz y coherente a todos los niveles, también a nivel nacional, europeo e internacional, con el fin de luchar eficazmente contra las violaciones de los derechos humanos cometidas por empresas internacionales, desde que se producen, y de abordar los problemas jurídicos derivados de la dimensión extraterritorial de las empresas y de su gestión, así como de disipar la consiguiente incertidumbre sobre la atribución de la responsabilidad por la violación de los derechos humanos. Pide a la Unión y a los Estados miembros que adopten normas claras que dispongan que las empresas establecidas en su territorio o jurisdicción deben respetar los derechos humanos en todas sus operaciones y en todos los países y contextos en los que operan, así como en lo referente a sus relaciones comerciales, también fuera de la Unión, considera que las empresas, según su tamaño y capacidades, incluidos los bancos y otras entidades financieras o de créditos que operan en terceros países, deben cerciorarse de que cuentan con sistemas para la evaluación de los riesgos y mitigación de los posibles efectos negativos relacionados con los derechos humanos, el trabajo, la protección del medio ambiente y los aspectos relacionados con catástrofes sobre operaciones y 
sus cadenas de valor; insta a los Estados miembros a evaluar periódicamente la adecuación de dichas normas y solventar las deficiencias.

Existe, pues, una obligación de las empresas de respetar los derechos humanos y también una obligación de los Estados de adoptar las normas necesarias para garantizar que las empresas respeten los derechos humanos.

\section{LA PROTECCIÓN DE LOS DERECHOS HUMANOS. EL TRATAMIENTO NORMATIVO}

\subsection{CONVENIOS INTERNACIONALES Y ÓRGANOS INTERNACIONALES GARANTES DE SU CUMPLIMIENTO}

La Declaración Universal de los Derechos Humanos (DUDH), adoptada por la Asamblea General de las Naciones Unidas el 10 de diciembre de 1948, apenas tres años después de terminada la Segunda Guerra Mundial, fue el primer instrumento que reguló los derechos humanos. Su valor declarativo e interpretativo (político, no jurídico) perdura con fuerza hoy en día. De la Declaración se desprende la siguiente definición de "derechos humanos".

Los derechos humanos son derechos inherentes a todos los seres humanos, sin distinción de nacionalidad, lugar de residencia, sexo, origen nacional o étnico, color, religión, lengua o cualquier otra condición. Todos tenemos los mismos derechos humanos, sin discriminación. Estos derechos son interrelacionados, interdependientes e indivisibles (ACNUDH).

La Declaración es, pues, la primera aproximación a la definición de los derechos civiles, políticos, económicos, sociales y culturales de todos y cada uno de nosotros, como pueden ser la igualdad ante la ley (artículo 7), la libertad de pensamiento, conciencia y religión (artículo 18), el derecho a la educación (artículo 26) o el derecho a participar y beneficiarse de la vida cultural y del progreso científico (artículo 27).

Desde su aprobación, los principios no vinculantes establecidos en la DUDH han sido concretados a través de más de 200 tratados internacionales y sus protocolos (estos sí con valor jurídico para aquellos Estados que los ratifican), así como de costumbres, principios generales del derecho internacional y otras normas sustantivas y procesales. Destacan el Pacto Internacional de Derechos Civiles y Políticos (PIDCP) y el Pacto Internacional de Derechos Económicos y Culturales (PIDESC), ambos aprobados en 1966, pero el listado es interminable: la Convención contra la Tortura y otros Tratos o Penas Crueles, Inhumanos o Degradantes (1984), la Convención sobre la Eliminación de todas las Formas de Discriminación contra la Mujer (1979) y la Convención sobre los Derechos de las Personas con Discapacidad (2006), incorporando 
también los derechos emergentes de tercera y cuarta generación, que han ido actualizando y complementando los derechos humanos reconocidos y sistematizados anteriormente a medida que surgían nuevos retos globales.

Todos estos instrumentos internacionales no tienen, sin embargo, ningún sentido si su adopción no va acompañada del establecimiento de órganos específicos que se encarguen del seguimiento y el control de la aplicación que hacen los Estados. De la mano de la aprobación de los diversos instrumentos vistos anteriormente se han ido creando en el marco de las Naciones Unidas unos comités especializados que supervisan las actuaciones de los Estados en el ámbito concreto de su competencia. La tarea de estos comités es diversa: examen de informes periódicos, de comunicaciones o quejas de particulares (lo que les da una función casi-contenciosa), de comunicaciones o quejas interestatales, investigaciones de oficio y visitas, y procedimientos de urgencia y alerta rápida, así como el importante Examen Periódico Universal, llevado a cabo en el seno del Consejo de Derechos Humanos y que analiza el cumplimiento por parte del Estado de todas las áreas de derechos humanos. El papel de estos comités como principales intérpretes de los tratados y protocolos es ampliamente reconocido, con respecto tanto a los mecanismos de seguimiento como los de control.

\subsection{La Unión Europea y el Consejo de Europa}

A nivel europeo existen dos instituciones supranacionales que han tenido un papel pionero en el mundo en el ámbito de la defensa de los derechos humanos. Se trata, por una parte, de la Unión Europea, el club de los 28 en el que el Parlamento, el Consejo, la Comisión y el Tribunal de Justicia tienen cada uno sus funciones propias en este ámbito. Por otra parte, el Consejo de Europa reúne 47 Estados europeos y su máximo representante en derechos humanos es el Convenio Europeo de los Derechos Humanos (CEDH), las violaciones son fiscalizadas por el Tribunal Europeo de Derechos Humanos (TEDH).

En el seno de la Unión Europea se adoptó, en 2000, la Carta de los Derechos Fundamentales de la Unión o Carta de Niza. La Carta, una colección muy garantista, en el momento de su adopción supera la clasificación de derechos civiles y políticos, por un lado, y económicos, sociales y culturales, por otro, y los agrupa junto con los de tercera y cuarta generación, basándose en los principios y valores de la Unión: dignidad, libertad, igualdad, solidaridad, ciudadanía y justicia.

Cuando entró en vigor el Tratado de Lisboa en el año 2009, los derechos, libertades y principios consagrados en la Carta pasaron a ser jurídicamente vinculantes y esta adquirió el mismo valor jurídico que los tratados (artículo 6 del Tratado de la Unión Europea ). La Carta puede ser invocada por los ciudadanos en relación con acciones provenientes de las instituciones de la Unión, así como a aquellas provenientes de los Estados miembros siempre que estén aplicando normativa europea. 
Igualmente, de acuerdo con la coherencia de políticas, la Unión Europea también se ha marcado como objetivo promover los derechos humanos más allá de sus fronteras por medio de las políticas de acción exterior.

En cuanto al seguimiento y control del cumplimiento de los derechos humanos, el Tratado de la Unión Europea, en el artículo 7, establece un mecanismo de control político de las violaciones de derechos humanos por medio del cual el Consejo puede decidir la suspensión de determinados derechos derivados los Tratados ante la existencia de una violación grave y persistente de los derechos del artículo 2 por parte de un Estado miembro. Sin embargo, este mecanismo sancionador ha tenido una aplicación casi nula desde su aprobación.

Aparte de eso, el Tribunal de Justicia de la Unión Europea, especialmente por medio de sus decisiones prejudiciales (artículo 267 del Tratado de Funcionamiento de la Unión Europea), ha creado una amplia jurisprudencia en el ámbito de la protección de los derechos humanos. Y lo ha hecho recordando los diversos instrumentos existentes, tanto nacionales como internacionales, como el derecho de la Unión, los convenios internacionales incluidos en los tratados, los derechos fundamentales reconocidos en las constituciones de los Estados miembros, etc. Dentro de esta recopilación de instrumentos destacan las repetidas menciones al Convenio Europeo de los Derechos Humanos. De hecho, el propio Tratado de Lisboa insta a la Unión Europea a adherirse, lo que permitiría a la ciudadanía dirigirse directamente al TEDH, un órgano especializado en la materia, por denunciar violaciones de derechos humanos por parte de las instituciones europeas (se trataría de un aspecto muy relevante dado que se ha demostrado que las denuncias ciudadanas son el verdadero núcleo de la protección de los derechos humanos) ${ }^{6}$.

Por último, todo ciudadano de la Unión o con residencia o sede social en uno de los Estados miembros puede acudir al defensor del Pueblo Europeo, directamente o por mediación de un miembro del Parlamento Europeo, con el fin de denunciar un acto de mala administración en la actuación de las instituciones comunitarias que atente contra los derechos humanos reconocidos en el derecho de la Unión (excepto el tue y el Tribunal de Primera Instancia).

\subsection{El ORDENAMIENTO ESPAÑOL}

La Constitución española establece explícitamente en el artículo 10.2 que "las normas relativas a los derechos fundamentales y a las libertades que la Constitución reconoce se interpretarán de conformidad con la Declaración Universal de Derechos Humanos y los tratados y acuerdos internacionales

6 Véanse al respecto Isabel Gallego CórColes, "Cláusulas sociales, contratación pública y jurisprudencia del TJUE", Contratación Administración Práctica, n. ${ }^{\circ} 113,2011$; y TeRESA MEDINA ARNAIZ, "La contratación pública socialmente responsable a través de la jurisprudencia del TJUE", REDA, n. ${ }^{\circ} 153$, pp. 1-20. 
sobre las mismas materias ratificados por España". Se reconoce, pues, el gran valor de la DUDH y otros tratados y protocolos en materia de derechos humanos, tanto a nivel interpretativo (el artículo 10.2 mencionado) como a nivel de aplicabilidad, dado que en virtud del artículo 96 los tratados internacionales forman parte del derecho interno español.

Esto es importante porque, si bien en principio los derechos fundamentales incluidos en la Constitución se consideran más garantistas que los derechos adoptados a nivel global, más genéricos, en ocasiones, a nivel internacional, adoptan acuerdos referentes a nuevos derechos y nuevos fenómenos de manera más rápida que a nivel español, demostrando que el ordenamiento interno no es siempre tan progresista como cabría esperar.

El Estado español ha ratificado la gran mayoría de instrumentos internacionales de derechos humanos de las Naciones Unidas, la Organización Internacional del Trabajo (OIT) y de la Organización de las Naciones Unidas para la Educación, la Ciencia y la Cultura (Unesco).

En España se habla de una tutela multinivel de los derechos humanos (también llamados derechos fundamentales), dado que existen diversos poderes públicos, y también privados, que contribuyen a configurar estos derechos. Así, no solo nos encontramos con una relación de derechos y libertades establecidos a nivel internacional por las Naciones Unidas y otras organizaciones, a nivel europeo por el Consejo de Europa y la Unión Europea, y a nivel nacional por la Constitución y leyes de su desarrollo, además de las interpretaciones judiciales respecto de los diversos textos normativos. En el ámbito público, también han sido las comunidades autónomas y los entes locales quienes han querido reconocer los derechos humanos por sí mismos y reforzar su efectividad a nivel subnacional ${ }^{7}$.

En cualquier caso, las vulneraciones de derechos humanos están sujetas al control por el Tribunal Constitucional o por la jurisdicción contenciosoadministrativa. Además, las figuras del defensor del Pueblo y el Ministerio Fiscal también son garantes de la protección de los derechos humanos en España, como existe igualmente en cada ministerio o agencia uno o varios departamentos que se encargan de velar por ellos. También instituciones a nivel autonómico tienen encomendada esta misión, como el defensor del Pueblo y los defensores sectoriales (del consumidor, del menor...), los departamentos correspondientes de cada consejería y, en algunos casos (Cataluña, Baleares, País Vasco), con comisiones parlamentarias específicas. Por último, cada vez

7 Si bien el Tribunal Constitucional ha dictaminado, a través de la sentencia 247/2007 (con cinco votos particulares disidentes), que no es competencia de los estatutos de autonomía establecer directamente derechos subjetivos que no estén ligados al sistema institucional determinado al nivel central, sino que los textos supremos autonómicos deben limitarse a "directrices, objetivos o mandatos" (o, como la misma institución menciona en la sentencia 31/2010, a "otros tipos de derechos, distintos de los derechos fundamentales"). 
es más frecuente la figura del defensor de los derechos humanos a nivel local, particularmente en Cataluña (llamado defensor del pueblo).

\section{CONTRATACIÓN PÚBLICA Y DERECHOS HUMANOS}

Una vez expuesto el marco general en el que se contienen los derechos humanos y sus mecanismos de definición y protección, procede ya entrar en la relación de los mismos con la contratación pública, y los mecanismos para llevar al seno de esta contratación la defensa de estos derechos.

La Directiva 2014/24/UE del Parlamento Europeo y del Consejo del 26 de febrero de 2014 sobre contratación pública, por la que se deroga la Directiva 2004/18/CE, representa la norma comunitaria básica en materia de contratación pública. La Directiva consagra el carácter instrumental de la contratación pública, dirigida a servir de apoyo a determinadas políticas públicas, como son el respeto al medio ambiente o determinados aspectos sociales. En este sentido, es especialmente ilustrativo el considerando número 2 del texto legal:

(2) La contratación pública tiene un papel clave en la Estrategia Europa 2020, establecida en la Comunicación de la Comisión del 3 de marzo de 2010 titulada "Europa 2020, una estrategia para un crecimiento inteligente, sostenible e integrador" (Estrategia Europa 2020), como uno de los instrumentos basados en el mercado que se deben utilizar para lograr un crecimiento inteligente, sostenible e integrador, garantizando a la vez un uso más eficiente de los fondos públicos. Con este fin, se deben revisar y modernizar las normas vigentes sobre contratación pública adoptadas de conformidad con la Directiva 2004/17/CE del Parlamento Europeo y del Consejo, y la Directiva 2004/18/CE del Parlamento Europeo y del Consejo, con el fin de incrementar la eficiencia del gasto público, facilitando en particular la participación de las pequeñas y medianas empresas (PYMES) en la contratación pública, y de permitir que los contratantes utilicen mejor la contratación pública en apoyo de objetivos sociales comunes. Asimismo, hay que aclarar determinadas nociones y conceptos básicos para garantizar la seguridad jurídica e incorporar determinados aspectos de reiterada jurisprudencia del Tribunal de Justicia de la Unión Europea relativa a la contratación pública.

Entre otros extremos, la Directiva, en su artículo 18, obliga a los Estados miembros a velar, durante la ejecución del contrato, por el cumplimiento de las obligaciones medioambientales y laborales contenidas en la normativa de aplicación.

Esta directiva ha permitido una materia de incipiente notoriedad, la de la introducción de cláusulas sociales en las diferentes fases de la licitación. Pues bien, lo que nos importa destacar es que, a partir de esta posibilidad, introducir cláusulas sociales, se debe trabajar para utilizar la doctrina referente a las cláusulas sociales como precedente y como referencia de encaje jurídico para la inclusión del respeto a los derechos humanos en la contratación pública. 
Teniendo en cuenta, obviamente, las diferencias entre las cláusulas sociales y los derechos humanos.

La Directiva 2014/24/UE, por otra parte, recoge la doctrina elaborada por el Tribunal de Justicia de la Unión Europea, que ha sido la impulsora de la introducción de las cláusulas sociales en la contratación pública. Esta doctrina es importante en la medida en que puede ayudar a interpretar el alcance del contenido de la propia directiva.

La doctrina jurisprudencial está contenida básicamente en las siguientes sentencias: sentencia del 20 de septiembre de 1988, Beentjes C-31/87; sentencia del 26 de septiembre de 2000, Comisión c República Francesa C-225/98; sentencia del 17 de septiembre de 2002, Concordia Bus Finland OY AB C-346/06, y sentencia del 17 de noviembre de 2015, Regiopost C-115/14.

La nueva Ley de Contratos del Sector Público (LCSP 2017) ha transpuesto al ordenamiento jurídico español las directivas del Parlamento Europeo y del Consejo 2014/23/UE y 2014/24/UE, del 26 de febrero de 2014, a las que hemos hecho referencia.

La LCSP 2017 no establece novedades notables en el impulso de la contratación pública sostenible, sobre todo en cuanto a los derechos de los trabajadores, así como el respeto al medio ambiente, materias que claramente inciden en el ámbito de los derechos humanos. En este sentido, el apartado $v$ de la exposición de motivos de la norma sí prevé que se pueden incluir condiciones especiales de ejecución y de adjudicación encaminados a garantizar los derechos humanos. Es la única mención a ellos de la norma, de manera pionera y favoreciendo la visión estratégica de la contratación pública a la que se ha hecho referencia. En concreto, se dice que

además, con el objetivo de favorecer el respeto hacia los derechos humanos y, en especial, hacia los derechos laborales básicos de las personas trabajadoras y de los pequeños productores de países en vías de desarrollo, se introduce la posibilidad de que tanto los criterios de adjudicación como las condiciones especiales de ejecución incorporen aspectos sociales del proceso de producción y comercialización en relación con las obras, los suministros o los servicios que deban facilitar de acuerdo con el contrato en cuestión, y en particular puede exigirse que este proceso cumpla con los principios del comercio justo establecido en el apartado 2 de la Resolución del Parlamento Europeo sobre comercio justo y desarrollo 2005/2245 (INI).

El texto final de la LCSP 2017, aunque es cierto que podría haber sido mucho más garante de los derechos humanos, incluye algunas iniciativas destacables, como la previsión expresa de la corrupción (artículo 1). Lo hace en forma de referencia al principio de integridad, otorgando efectos jurídicos a un principio ético como el de la honradez, que ha sido reconocido en la Convención de las Naciones Unidas contra la Corrupción, y de acuerdo con el artículo 41 de la Carta de los Derechos Fundamentales de la Unión Europea (que, 
recordemos, está integrada al ordenamiento interno por méritos de la Ley 1/2008 del 31 de julio).

La LCSP 2017 asume de la directiva transpuesta la referida consideración de cómo utilizar la contratación pública como instrumento de políticas medioambientales, sociales y de innovación y desarrollo, y declara en el artículo 1 que estas medidas favorecen la mejor relación calidad y precio en el contrato. A partir de aquí, los legisladores estatal y autonómico pueden desarrollar estos principios, pero a su vez las administraciones contratantes pueden usar su potestad de contratación para, en las diversas fases de la contratación, introducir mecanismos que garanticen que las empresas contratistas respetaran en su actuación los derechos fundamentales. A esta segunda cuestión se dedican las páginas siguientes.

\section{DOS EXPERIENCIAS CONCRETAS: GUIIAS PARA LA PROTECCIÓN Y LA REALIZACIÓN DE LOS DERECHOS HUMANOS EN LA CONTRATACIÓN PÚBLICA}

Las reflexiones que se han hecho en las páginas anteriores ponen de manifiesto la necesidad de conectar el ejercicio de la contratación pública con la defensa de los derechos humanos. Si como hemos dicho los derechos humanos son el pilar de nuestra vida colectiva y, por otro lado, la contratación pública supone el destino de cantidades ingentes de dinero público hacia el sector privado, parece lógico reclamar que la contratación cumpla con la función estratégica de ponerse al servicio de la exigencia del respeto a los derechos humanos por parte de las empresas contratistas.

Esta conexión entre el medio, la contratación y el fin, la defensa de los derechos humanos, obliga a tener en cuenta el régimen jurídico singular de la contratación pública, dominado por los principios de concurrencia licitatoria, selección de la mejor oferta y correcta ejecución. Por tano, la defensa de los derechos humanos deberá articularse en las diversas fases de la contratación, de modo que se logre imponer a las empresas el respeto y la promoción de los derechos humanos, sin que ello suponga alterar las reglas propias del proceso de contratación y de la ejecución de los contratos.

Este equilibro entre dos fines de interés general (los propios de la contratación pública y la defensa de los derechos humanos), que concurren cuando se debe adjudicar un contrato y garantizar su correcta ejecución, plantea importantes problemas en el momento de llevar adelante un proceso de contratación. Con el fin de señalar estos problemas, pero a su vez ofrecer posibles vías para superarlos, damos cuenta de dos experiencias con las que se ha tratado de avanzar en el cumplimiento de la función estratégica de la contratación consistente en la protección y desarrollo de los derechos humanos: la Guía del ayuntamiento de Barcelona para la protección y la realización de los derechos humanos en la contratación pública y la Guía para 
el respeto de los derechos humanos en los procesos de contratación pública de suministros y servicios de seguridad del Observatori de Drets Humans i Empreses a la Mediterrània (ODHE).

\subsection{La Guía PARA La PROTECCIÓN Y LA REALIZACIÓN DE LOS DERECHOS

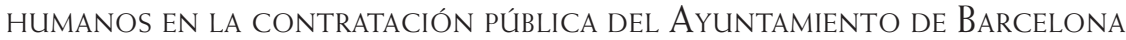

a. Principios generales. La Guía aprobada por el Ayuntamiento de Barcelona, que fue presentada el 16 de noviembre de 2017, trata de facilitar a los órganos de contratación la incorporación de cláusulas sociales tendentes a la garantía de los derechos humanos por parte de las entidades contratistas en todas las fases del procedimiento de contratación.

Esta Guía, aprobada por el Ayuntamiento de Barcelona, se dirige a los poderes locales de Cataluña, a las administraciones locales y a sus empresas municipales con participación mayoritaria pública. Su vocaciones es que también pueda ser un texto de referencia para el resto de poderes locales de España.

En cuanto a la parte que contrata con la administración, la Guía se dirige a los contratistas y los subcontratistas. El contratista debe garantizar que los subcontratistas cumplen con las condiciones de ejecución establecidas en esta Guía. En todo caso, los subcontratistas están obligados ante el contratista, que asume toda la responsabilidad en la ejecución del contrato ante la Administración.

Importa destacar que estas cláusulas pueden introducirse como criterios de admisión, criterios de adjudicación o condiciones especiales de ejecución de cumplimiento obligatorio a lo largo de la ejecución del contrato, atendiendo en cada momento a las exigencias propias de la normativa de contratación pública, en la actualidad, a lo dispuesto en la LCSP.

Por otra parte, los derechos a proteger son los derechos humanos reconocidos en determinados textos legales de aplicación en España, concretamente los siguientes textos legales:

- Convenio Europeo de los Derechos Humanos, Consejo de Europa, 1950.

- Carta Social Europea, Consejo de Europa, 1996.

- Pacto Internacional de Derechos Económicos, Naciones Unidas, 1966.

- Pacto Internacional de los Derechos Civiles y Políticos, Naciones Unidas, 1966.

- Convenio Europeo sobre el Ejercicio de los Derechos de los Niños, Consejo de Europa, 1996.

- Carta de los Derechos Fundamentales, Unión Europea, 2000.

- Convenio de Protección de los Niños contra la Explotación y el Abuso Sexual, Consejo de Europa, 2007.

- Convenios básicos de la OIT.

- Constitución española de 1978, artículos 10 a 38. 
No forman parte de la Guía la incorporación de cláusulas sociales como las relativas a la eliminación de la discriminación por razón de género, la lucha contra el paro, la protección de la salud en el lugar de trabajo u otras similares que, si bien tienen relación directa con los derechos fundamentales (igualdad, derecho al trabajo o a la salud), tienen un régimen especial, dado que forman parte de las condiciones generales de carácter social que también pueden incorporarse a la contratación como una manifestación más de la función estratégica de la contratación pública.

El modo a través del cual se trata de lograr la protección de los derechos humanos reconocidos en los textos citados tiene un triple nivel. Por un lado, se incluyen medidas preventivas con las que se logre evitar el acceso a la contratación a las empresas que vulneren los derechos humanos; en segundo lugar, se trata de actuar con medidas positivas a favor de las empresas que garanticen la protección y la realización de los derechos humanos y, en tercer lugar, se penaliza a las empresas contratistas que vulneren estos derechos.

La vulneración de los derechos humanos no se dará por muchas veces en la propia empresa contratante, sino que quien los vulnera son las empresas subcontratistas. Las empresas contratantes, líderes en ocasiones en su sector de actividad, se colocan en un extremo de la cadena de producción, mientras que quien sufre la vulneración de sus derechos humanos son los individuos o colectividades que trabajan para la empresa contratista en las empresas subcontratistas, que se sitúan el final de la cadena de producción. En muchas otras ocasiones la vulneración de los derechos humanos se produce en filiales de la empresa contratista que actúan más allá de las fronteras de la administración contratante ${ }^{8}$.

A modo de ejemplo, se pueden citar como prácticas que comportan la vulneración de derechos humanos por empresas contratistas las siguientes:

- Tratos inhumanos o degradantes a los empleados (artículo 3 del Convenio Europeo de Derechos Humanos, artículo 4 de la Carta de Derechos Fundamentales de la Unión Europea, artículo 7 del Pacto Internacional de Derechos Civiles y Políticos).

- Discriminación de los trabajadores (artículo 7 del Pacto Internacional de Derechos Económicos, artículo 21 de la Carta de Derechos Fundamentales de la Unión Europea, artículo 3 del Pacto Internacional de Derechos Civiles y Políticos).

- Trabajos forzados u obligatorios (artículo 4 del Convenio Europeo de Derechos Humanos, artículo 5 de la Carta de Derechos Fundamentales de la Unión Europea, artículo 7 del Pacto Internacional de Derechos Civiles y Políticos).

8 Véase Elena Cristina Tudor, "La contratación pública y la promoción de los derechos humanos", Revista Pensamiento Jurídico, vol.10, n. ${ }^{\circ}$ 2, 2016. 
- Prohibición de crear o formar parte de sindicatos libres (artículo 8 del Pacto Internacional de Derechos Económicos, artículo 11 del Convenio Europeo de Derechos Humanos, artículo 12 de la Carta de Derechos Fundamentales de la Unión Europea, artículo 22 del Pacto internacional de Derechos Civiles y Políticos).

Las medidas a adoptar, cuando tratan de evitar la participación de empresas en la contratación o pretenden sancionarlas por su conducta, parten de la afirmación de que la empresa contratista ha vulnerado los derechos humanos. Este hecho suscita una cuestión relevante y compleja jurídicamente, pues no es fácil responder a las siguientes preguntas: ¿cuándo la Administración contratante puede entender que una empresa contratista ha vulnerado los derechos humanos? Por ejemplo, tratándose de una empresa de seguridad, ¿cuándo se puede entender acreditado que ha cometido torturas en una prisión en Irak? o ¿cuándo una empresa de suministro de agua puede entenderse culpable por negar el derecho al agua en determinadas comunidades locales?

Pues bien, en la Guía se afirma que la vulneración de los derechos humanos que permite adoptar las medias que se proponen solo se entiende cometida cuando exista una resolución administrativa firme o sentencia firme que condene la empresa por vulnerar los derechos humanos.

La resolución administrativa firme puede haber sido dictada por una administración del Estado español o de otro Estado democrático, y siempre debe hacer referencia a condenas por la vulneración de derechos humanos contenidos en las disposiciones antes mencionadas.

La sentencia firme puede haber sido dictada por tribunales españoles ordinarios o el Tribunal Constitucional, o por tribunales de otros países, también ordinarios o constitucionales, pero siempre que se trate de sentencias en las que se condene por la vulneración de derechos humanos contenidos en las disposiciones mencionadas antes.

También se entiende cometida una vulneración de los derechos humanos cuando exista una condena realizada por una organización internacional de especial relevancia y reconocida por el Estado español ${ }^{9}$.

9 Actualmente, en el Reino Unido no solo son los tribunales los que pueden dictaminar sobre una violación de derechos humanos que tenga efectos en la contratación pública. Así, el Comité de Derechos Humanos del Parlamento del Reino Unido, en su Informe de derechos humanos y empresas de 2017 recuerda que "las empresas, de las que los tribunales o el Punto de Nacional de Contacto [de la OCDE] hayan determinado que han cometido abusos, o un acuerdo extrajudicial indique que han cometido abusos de derechos humanos, también deberían excluirse de los contratos con el sector público por un periodo definido y significativo". En este sentido, la organización Lawyers for Palestinian Human Rights denunció en 2013 que la empresa de seguridad G4S había cometido violaciones de derechos humanos en los Territorios Palestinos Ocupados. A raíz de esta denuncia, el Punto de Contacto Nación de la OCDE en el Reino Unido pudo constatar estas violaciones. Sin embargo, este hallazgo no fue suficiente para impedir la adjudicación de un nuevo contrato 
b. Ámbito material de aplicación. La Guía tiene como objeto todos los contratos públicos, ya sean de derecho administrativo o de derecho privado, adjudicados por las entidades contratantes a que se ha hecho referencia anteriormente.

Las medidas para favorecer los derechos humanos se pueden incluir, en función de las características del contrato, en las siguientes fases del procedimiento de contratación:

- Fase de preparación: Definición de condiciones especiales de contratación.

- Fase de selección: Criterios de solvencia y admisión.

- Fase de adjudicación: Valoración de las ofertas de los licitadores.

- Fase ejecución: Condiciones de ejecución, sanción y resolución.

Las medidas establecidas en esta Guía se incluirán en los pliegos de cláusulas administrativas particulares (PCAP) o en los pliegos de condiciones técnicas, y la figura del responsable del contrato es quien debe hacerlas efectivas.

c. Medidas que se pueden introducir en el proceso de contratación. La Guía se debe considerar como el establecimiento de pautas orientativas de actuación que el órgano de contratación debe concretar atendiendo al tipo y cuantía de contrato.

Una primera cuestión de carácter general para tener en cuenta es que en principio las medidas de carácter social o medioambiental que se adoptan como manifestación de la función estratégica de la contratación deben guardar relación con el objeto del contrato. Así lo establecen la Directiva 2014/24/ UE y la jurisprudencia comunitaria (entre otras, la sentencia sTJu Wienstram C-448/01). En el mismo sentido, el artículo 145.6 de la LCSP establece que "se considera que un criterio de adjudicación está vinculado al objetivo del contrato cuando se refiera o integre las prestaciones que deban realizarse en virtud de dicho contrato, en cualquiera de sus aspectos y en cualquier etapa de su ciclo de vida". Así pues, las condiciones que se puedan introducir en las fases de preparación, admisión, selección o ejecución del contrato deberían estar referidas específicamente a las obras, suministros o servicios objeto del contrato.

No obstante, creemos que cuando se trata de la protección de los derechos humanos, las medidas que pueda adoptar la Administración deben considerarse como intervenciones de carácter transversal que deben poder estar presentes en todos los contratos, al margen de su relación con el objeto concreto del mismo. No se trata de cláusulas sociales que impongan obligaciones de hacer a los contratistas y que, como tales, tengan que mantener una relación concreta con el objeto del contrato, como la prestación de un servicio de transporte con energía verde, o la prestación de otro servicio por parte de personas con dificultades de inserción laboral. Toda empresa que tenga la intención de contratar con la Administración debe respetar los derechos humanos. Lo que se impone

público a esta empresa por parte del Gobierno, lo que fue objeto de una dura crítica por parte de la organización. 
es, pues, un deber de respeto de los derechos humanos, un comportamiento ético y una prohibición de hacer. Por esta razón se introducen medidas en el proceso de contratación que pretenden garantizar este comportamiento, como medidas transversales y objetivas que son concreción de una finalidad estratégica de la contratación pública. Cuestión diversa es que estas medidas sí deben respetar los principios fundamentales de la contratación comunitaria, como la libre concurrencia, la libertad de acceso a las licitaciones, la publicidad y la transparencia de los procedimientos, la no discriminación y la igualdad de trato entre los candidatos.

d. Medidas que se pueden introducir en la preparación del contrato. El órgano de contratación, en la definición de las cláusulas esenciales, establecerá la obligación del respeto de los derechos humanos incluidos en las normas de referencia.

e. Medidas que se pueden introducir como criterios de admisión de los contratistas. La primera medida que se puede establecer es que, de acuerdo con lo establecido en los artículos 71 y 72 de la LCSP 2017, no pueden contratar las empresas que, según lo establecido en el apartado 2.2 de la Guía,

- Hayan sido condenadas por tráfico de seres humanos.

- Hayan sido condenadas por medio de una sanción firme por infracciones en materia de extranjería ${ }^{10}$.

La prohibición de contratar y la determinación de su duración se llevarán a cabo de conformidad con el artículo 72 de la LCSP 2017 $7^{[11]}$

En segundo lugar, el órgano de contratación, como condición para que las empresas participen en la licitación, podría solicitar la aportación de la documentación necesaria que acredite el respeto de los derechos humanos. En concreto, de acuerdo con esta cláusula, los licitadores deben manifestar el cumplimiento de los derechos humanos mediante la presentación de una declaración responsable.

La declaración responsable es un documento suscrito por el licitador en el que manifiesta que, en toda su actividad y en la de las entidades filiales que dependan, se respetan los derechos humanos y que se mantendrá este respecto a lo largo de todo el periodo de ejecución del contrato. La declaración responsable debe ser aprobada por el nivel más alto directivo de la empresa, debe precisar qué actuaciones se llevarán a cabo para garantizar el respeto de los derechos humanos y se debe hacer pública y difundir entre todo el personal de la empresa. También se ha de prever un monitoreo interno del

10 Se entiende que los casos de prohibición para contratar solo pueden aplicarse si están contemplados en la ley, y por ello se limitan a estos supuestos.

11 Sobre la posible introducción de prohibiciones de contratar, véase FERNANDO AcuÑa, "Las graves vulneraciones de derechos humanos como prohibiciones de contratar", Observatorio de Contratación Pública, 13 de septiembre de 2017. Disponible en línea: http://www.obcp.es/ opiniones/las-graves-vulneraciones-de-derechos-humanos-como-prohibicion-de-contratar. 
cumplimiento de las actuaciones comprometidas y prever las reacciones ante los incumplimientos que se puedan detectar.

Si un licitador no aporta la declaración responsable en caso de que se haya exigido en los PCAP, su propuesta no se podrá admitir, de acuerdo con la previsión general del artículo 95 de la LCSP 2017. El cumplimiento del respeto y la protección de los derechos humanos puede definirse en los PCAP como condición especial de ejecución del contrato, de obligación esencial del contrato (artículo 200.3 en relación con el artículo 211.f de la LCSP 2017). De esta forma, la falsedad o el incumplimiento en el contenido de la declaración responsable comportarán, una vez adjudicado el contrato, la resolución contractual. De acuerdo con el artículo 202.4 de la LCSP 2017, además, el cumplimiento de las condiciones especiales de ejecución es extensible a los subcontratistas.

En ocasiones, dependiendo del objeto del contrato, el tipo de contrato, los posibles licitadores y otros criterios similares, la exigencia de ciertas medidas a las empresas licitadoras y/o contratantes puede ser una tarea (casi) imposible. Así, por ejemplo, acreditar que a lo largo de la cadena de producción las diversas empresas cumplen con los derechos humanos. Por este motivo, hay que tener presente que, en ocasiones, dependiendo del objeto del contrato, el tipo de contrato, los posibles licitadores y otros criterios similares, puede convenir más hablar de "diligencia debida", de requerir a las empresas licitadoras y/o contratantes una diligencia debida efectiva en la relación con sus proveedores.

En tercer lugar, los pliegos de condiciones administrativas particulares (PCAP) también pueden establecer como condición de participación en la licitación que los licitadores incorporen a su oferta la cadena de suministros. El objetivo es identificar todas las empresas que forman parte de la producción del bien o servicio objeto del contrato y que se pueda comprobar que estas empresas son respetuosas con los derechos humanos. La principal finalidad de esta exigencia es disuadir la presentación de las empresas que en su cadena de suministro puedan incluir empresas que vulneren los derechos humanos. Esta exigencia encuentra apoyo normativo en el artículo 89.1.g de la LCSP 2017.

Si al informar de la cadena de producción se identifican empresas que han sido condenadas por sentencia firme (u otro de los medios comentados anteriormente) como vulneradoras de los derechos humanos, se requerirá al licitador que rompa la relación con ellas y, en caso de que la mantenga, se le excluirá del procedimiento de licitación.

f. Medidas que se pueden introducir como criterios de adjudicación ${ }^{12}$. El anuncio de licitación y los PCAP pueden establecer que los licitadores incorporen a la

12 Véanse sobre esta cuestión Isabel Gallego CórCOLES, "Las cláusulas sociales como criterio de adjudicación", Contratación Administrativa Práctica, n. ${ }^{\circ}$ 152, 2017; y GloRIA ZúNíga Rial, 
oferta un programa de compliance, responsabilidad corporativa, de la empresa en el que se haga referencia de forma específica a la protección y la realización de los derechos humanos. El programa de compliance, para ser valorado positivamente, debe incluir un modelo interno de organización y gestión que garantice la protección y la defensa de los derechos humanos. Los PCAP pueden ponderar el contenido exigible al programa de compliance atendiendo al tipo y cuantía del contrato.

La puntuación de la aportación de un documento de compliance debe ser limitada para evitar que se pueda considerar discriminatoria dado el coste por suponer la elaboración de este documento por parte de empresas de tamaño medio y pequeño, pero creemos que se puede exigir su aportación y valoración.

De acuerdo con las previsiones del artículo 127.2 LCSP 2017, también se puede establecer como criterio de adjudicación la aportación del certificado ISO 20400 como etiqueta social, en la medida en que proporciona información sobre la estrategia de adquisiciones y procesos de las empresas, definiendo los principios de sostenibilidad de las adquisiciones en términos de transparencia, respeto de los derechos humanos y comportamiento ético.

g. Medidas que se pueden introducir en la ejecución del contrato. Los órganos de contratación podrán establecer, como condición especial en relación con la ejecución del contrato, el respeto de los derechos humanos por parte de las empresas licitadoras y sus subcontratistas a lo largo de todo el proceso de ejecución del contrato. Esta condición debe constar en el anuncio de licitación y los PCAP.

Las condiciones especiales se precisarán, además, en el documento de formalización del contrato. Son obligaciones que el licitador seleccionado debe cumplir en la ejecución del contrato. En este caso, evidentemente, la obligación es el respeto de los derechos humanos.

El incumplimiento de la condición esencial de respetar los derechos humanos por parte de la empresa adjudicataria puede comportar que sea condenada por vulneración de los derechos humanos en actuaciones que se hayan producido antes o durante la ejecución del contrato.

El incumplimiento de la condición especial puede suponer la imposición de una sanción, de acuerdo con los artículos 192.1 y 202.1 de la LCSP 2017, o la resolución del contrato, de acuerdo con los artículos 211.f de la LCSP 2017.

h. Otras obligaciones del adjudicatario en materia de protección de los derechos bumanos. Además de estar obligado a cumplir todas las obligaciones establecidas en la normativa vigente, el adjudicatario también deberá cumplir las obligaciones esenciales siguientes:

"El tratamiento de las cláusulas sociales en la normativa reguladora de la contratación pública. Su consideración como criterios de adjudicación de los contratos administrativos", Direitto, vol. 17, n. ${ }^{\circ} 2,2008$, pp. 65-90. 
- Debe aceptar que los servicios de la entidad contratante puedan realizar las comprobaciones necesarias para verificar que cumple con el respeto de los derechos humanos. En especial, el adjudicatario debe colaborar activamente con el responsable del contrato a la hora de acreditar el cumplimiento de estas obligaciones.

- Debe comunicar al órgano de contratación las posibles vulneraciones de derechos humanos de las que tenga constancia, tanto en los procesos de adjudicación del contrato como durante la ejecución del contrato. En este sentido, el adjudicatario debe aportar la información que le sea solicitada con el fin de acreditar el cumplimiento de los derechos humanos, así como la que la legislación de transparencia y los contratos del sector público impongan a los adjudicatarios.

- Debe transmitir al órgano de contratación la cadena de valor relativa a todo el proceso de ejecución del contrato.

- Estas obligaciones pueden ser exigidas igualmente a todos los subcontratistas que participen en la ejecución del contrato.

Como se ha adelantado, el incumplimiento de estas obligaciones ya supondría, sin necesidad de una mayor previsión en los pliegos, una causa de resolución del contrato, dado que así lo prevé la normativa de aplicación. Sin embargo, como es práctica habitual y con el ánimo de reforzar el carácter pionero y didáctico de esta Guía, esta causa de resolución se podría disponer expresamente a los pliegos.

i. Causas de resolución del contrato. El incumplimiento de las obligaciones en materia de derechos humanos previstas en los pliegos.

j. Medidas de seguimiento y control. Una vez formalizado el contrato, la persona responsable (artículo 62 de la LSCP 2017) debe supervisar de forma periódica el cumplimiento de las obligaciones que se hayan impuesto como condiciones esenciales a la empresa adjudicataria y, en su caso, a los subcontratistas.

Pueden añadirse otros mecanismos de supervisión para un mayor seguimiento y control por parte de la Administración pública de la ejecución de los contratos. Así, por ejemplo, se puede establecer que, dentro del proceso de ejecución del contrato, el adjudicatario responda un cuestionario de seguimiento, con un modelo de evaluación, o bien que el responsable de seguimiento realice una inspección de instalaciones y procedimientos, o la participación obligatoria por parte del adjudicatario y sus subcontratistas (en la medida de lo posible) en talleres sobre derechos humanos.

Es importante remarcar aquí que, si bien en ocasiones la violación de los derechos humanos puede constituir un motivo de resolución del contrato, los procesos de seguimiento y control también pueden servir para corregir los impactos adversos a los derechos humanos que se hayan identificado (compensación financiera, reparación, etc.), a fin de favorecer un cambio en el comportamiento de los adjudicatarios y una mayor concienciación sobre la necesidad de cumplimiento con los derechos humanos. En este sentido, hay que actuar de acuerdo con el principio de proporcionalidad, medir el grado de voluntariedad y conocimiento del comportamiento empresarial, e introducir 
medidas que no necesariamente tengan que ser penalizadoras (pueden ser también correctoras o disuasivas) ${ }^{13}$.

En las funciones de seguimiento y control también tiene especial relevancia el papel de las ONG y otras plataformas civiles, que, sin potestades orgánicas, sí podrían tener un papel importante como denunciantes e informadores de las administraciones. También pueden actuar con estas mismas finalidades el Síndic de Greuges o los síndicos municipales.

Como un buen ejemplo de supervisión por terceros, ajenos a las administraciones, puede mencionarse la fundación Electronics Watch, organización de supervisión independiente que ofrece a las instituciones afiliadas un servicio de monitorización independiente sobre las condiciones de trabajo en las fábricas donde se producen los bienes objeto del contrato (siempre en el ámbito de la electrónica). La fundación ha elaborado unas cláusulas de ejecución del contrato que se hacen públicas, ya los pliegos, y que contienen un código de normas laborales que regirán el monitoreo.

Así, por ejemplo, los contratistas tienen obligaciones como divulgar el nombre de las fábricas de ensamblaje y el de las fábricas de alto riesgo de componentes, así como un inventario químico de cada fábrica y producto o componente; permitir el acceso a la fábrica después de la detección del riesgo de incumplimiento, elaborar un informe sobre la estrategia de salarios dignos y, cuando sea necesario, elaborar un informe sobre la corrección del incumplimiento de algunas de las medidas ${ }^{14}$.

13 En el ámbito de la responsabilidad social corporativa, la ciudad de Malmö, en Suecia, aplica un exitoso sistema de verificación y control de la ejecución de los contratos públicos por parte de los contratistas. Si bien al inicio este sistema se aplicó de manera piloto en sectores como el material informático, mobiliario y material de oficina, se pretende ir incorporando nuevos sectores. El sistema se basa en cuatro elementos:

- El código de conducta: una lista de compromisos que los licitadores deben suscribir como parte de la oferta que presentan. La no aceptación implica su exclusión automática.

- El cuestionario de seguimiento: dentro del proceso de gestión del contrato, los proveedores deben responder un cuestionario a los cuatro meses de la adjudicación. Con el documento, se adjunta una guía orientativa que explica cómo se debe responder.

- El modelo de evaluación: sirve para que el municipio pueda evaluar las respuestas del cuestionario de seguimiento, como parte del mismo proceso de gestión del contrato.

- Las inspecciones: en algún momento, todos los proveedores deben someterse a una inspección de sus instalaciones.

Este sistema de verificación y control que Malmö comparte con otros municipios suecos les ha permitido ahorrar tiempo y recursos financieros, así como intercambiar información esencial sobre las empresas licitadoras y contratistas. Se ha comprobado que estas no han respondido negativamente (de hecho, se cree que se animan a mejorar sus actividades de contratación) y, además, que los costes de la contratación no han aumentado a pesar de la introducción de este sistema de verificación y control.

14 En septiembre de 2017, Electronics Watch publicó una guía para ayudar a los contratistas a cumplir las condiciones contractuales de diligencia debida efectiva por parte del contratista, a través del sistema "Cumplimiento o justificación", por lo que solo en caso de no colaborar 
4.2. La Guía para el Respeto de los derechos humanos en los procesos de CONTRATACIÓN PÚBLICA DE SUMINISTROS Y SERVICIOS DE SEGURIDAD

del Observatori de Drets Humans i Empreses a la Mediterrània (odhe)

Por último, queremos hacer una breve mención de otro ejemplo práctico con el que se trata de hacer efectivo el principio de la función estratégica de la contratación pública, aplicado en este caso a los contratos de suministros y servicios de seguridad.

La demanda de servicios de seguridad privada ha tenido en los últimos años un gran crecimiento. Estos servicios tienen un rasgo propio que los hace susceptibles de incurrir con mayor facilidad en violaciones de los derechos humanos, ya que la actividad que se presta implica de forma directa o indirecta el uso de la fuerza. Por ello es importante que en este sector de actividad las administraciones contratantes sean especialmente cuidadosas en exigir el respeto de los derechos humanos a las empresas con las que contratan, ya sean empresas que prestan servicios de seguridad o fabrican productos de seguridad.

La "Guía para el respeto de los derechos humanos en los procesos de contratación pública de suministros y servicios de seguridad" del Observatori de Drets Humans i Empreses a la Mediterrània, de noviembre de 2017, da cuenta de una serie de propuestas para alcanzar estos objetivos de contratación estratégica, y también menciona que el Gobierno español ha adoptado una serie de principios rectores en el Plan Nacional de Derechos Humanos y Empresas, comprometiéndose a incluir cláusulas de respeto a los derechos humanos en la contratación de servicios militares y de seguridad privados, de acuerdo con los principios básicos de Naciones Unidas sobre el empleo de la fuerza y las armas de fuego.

Estos criterios, que se deben aplicar en la contratación pública de este sector, deben tener en cuenta que los contratos en materia de defensa y seguridad pública se rigen por la Ley $24 / 2011$ del $1 .^{\circ}$ de agosto de contratos del sector publico en los ámbitos de defensa y de la seguridad.

El documento que comentamos identifica cuatro casos de empresas de este sector de actividad a las que se imputa la vulneración de derechos humanos en diversos conflictos internacionales. Son L3 Technologies, Prosegur, Indra Sistems S.A. y Regal 53 España S.L. Pero lo que nos importa destacar del documento son los criterios que establece para tratar de hacer efectivo el respeto de los derechos humanos en los procesos de contratación pública cuando se pueden dar los supuestos que se denuncian en estos cuatro casos. Pautas y criterios de actuación que, como veremos, tienen una estrecha semejanza con los que se contienen la Guía del Ayuntamiento de Barcelona comentada.

con EW según sus capacidades y la ayuda de la fundación el contratista puede verse expuesto a una resolución del contrato. La guía para los contratistas se puede consultar aquí: http://electronicswatch.org/guia-per-als-contractistes-setembre-de-2017_2525991.pdf. 
Las cláusulas de contratación pública que se proponen nacen del análisis de la normativa aplicable, el sector de defensa y seguridad pública, y los impactos sobre los derechos humanos producidos por empresas de ese ámbito. El objetivo principal es proponer cláusulas que puedan ser incorporadas en los procesos de contratación pública para promover la protección de los derechos humanos.

Al igual que en la Guía de Barcelona, las cláusulas se distribuyen en las siguientes fases de la contratación: preparación del contrato, criterios de admisión, condiciones de adjudicación, condiciones especiales de ejecución, y seguimiento y control.

Dentro de la fase de preparación del contrato, se proponen las siguientes medidas:

- Favorecer procedimientos abiertos con anuncio de las licitaciones, las adjudicación y el seguimiento para favorecer la transparencia del sector militar y de seguridad.

- Determinar el objeto de la contratación desde la perspectiva de una seguridad pública al servicio de las personas y los derechos humanos.

- Incluir evaluaciones de riesgos por parte de la Administración pública para determinar el impacto de un posible proceso de contratación pública antes de abrir la convocatoria. Esta evaluación previa contribuirá, además, a definir mejor las características del contrato.

- Definir los principios del sistema de contratación de la autoridad contratante para determinar los estándares de derechos humanos aplicables y otros valores como la transparencia.

- Establecer una estructura de los órganos y responsabilidades en el proceso de contratación, incluyendo la posibilidad de realizar consultas a actores especializados a nivel temático y geográfico.

- Definir un sistema de evaluación adecuado que valore al menos: la capacidad de la empresa (solvencia, políticas internas, historia y registro de conducta pasada), trabajadores (formación en derechos humanos y DIH, forma física y psicológica, registro de conducta pasada) y equipo (certificaciones técnicas, almacenamiento, adquisición legal, protocolos de uso).

Como medidas a adoptar en la fase de admisión:

- Aportación de declaración responsable, firmada por altos cargos de la empresa, que detalle que la empresa y sus subcontratistas no están condenadas por vulneración de derechos humanos a través de sentencia judicial firme (tribunales nacionales o internacionales), resolución administrativa firme o acuerdo extra-judicial de acuerdo al ordenamiento jurídico español y/o tratado internacional subscrito por el gobierno español, o que los productos y servicios que se contratan en esta licitación no han sido previamente probados contra población civil y/o en zonas afectadas por conflicto armado y/o ocupación ilegal $_{i}$ o que los trabajadores de la empresa licitadora y subcontratistas no han sido condenados por actos criminales o graves faltas profesionales; o que los 
trabajadores de la empresa y sus subcontratistas han sido formados en materia de derechos humanos y derecho internacional humanitario.

- Aportación de toda la cadena de suministro de la empresa licitadora para el suministro de la obra y servicio, indicando quiénes son todos los subcontratistas que participan y la ubicación de los mismos.

Como condiciones para la adjudicación se señalan las siguientes:

- Presencia, en el sí del contratista, de programas de debida diligencia para investigar y reparar las posibles vulneraciones de derechos humanos que se puedan producir durante la ejecución del contrato.

- Realización de evaluación de riesgos de impactos ambientales, sociales y respeto de derechos humanos sobre población afectada directa o indirectamente por las actividades a desarrollar durante el contrato, prestando especial atención a aquellas fases de la cadena de suministro que se realicen en zonas afectadas por conflicto armado donde el riesgo de vulneración de derechos humanos es aún mayor.

- Licencias y protocolos para el uso y mantenimiento de armas (manual de armas).

- Presencia de protocolos de reglas de enfrentamiento o políticas del uso de la fuerza que respeten los derechos humanos y estén compartidos por toda la organización.

- Disposición de protocolos de selección y contratación que respete los derechos laborales y la igualdad de condiciones, así como mecanismos de evaluación continua física y psicológica de los trabajadores.

- Presencia de planes de formación sobre los derechos humanos, DIH, integridad y concienciación ética, no discriminación racial o sexual, y prevención de acoso sexual entre los trabajadores de la empresa.

- Documentación que garantice la solvencia necesaria para mantener el suministro durante el servicio y/o suministro desde la investigación, lugar de producción, transporte y destrucción, respetando en todas las fases los derechos humanos de las personas donde se desarrollen las operaciones de la cadena de suministro y se respete la normativa nacional de comercio de armas y otros materiales de seguridad.

- Disposición de certificados de "buena reputación" por parte de otras administraciones públicas nacionales o internacionales.

- Disposición de certificaciones técnicas que cumplan los estándares europeos de los equipos y etiquetado de los materiales militares y de seguridad con información del lugar de producción.

- Presencia de sistemas de monitoreo interno de la organización, específicamente políticas y protocolos de recursos humanos que respeten los derechos laborales, departamento de ética de la empresa y protección de alertadores, capacidad investigadora interna, políticas disciplinarias y sancionadoras, planes de formación en los códigos de conducta internos. 
Como condiciones especiales durante la ejecución del contrato:

- El cumplimiento de las garantías de solvencia para asegurar la información sensible y el mantenimiento de todo el suministro y/o servicio, sin que se produzcan faltas profesionales que pongan en riesgo esta capacidad.

- El cumplimiento y la promoción de los derechos humanos previstos en los tratados suscritos por el Estado y en otras disposiciones de aplicación tanto a nivel nacional como internacional, y aceptación que los servicios de la entidad contratante puedan realizar cuantas comprobaciones consideren necesarias para velar por este cumplimiento. En especial, se colaborará activamente con el responsable del contrato en el momento de acreditar el cumplimiento de estas obligaciones.

- El cumplimiento de todas las políticas internas de la empresa, personal y equipos valoradas como criterios de adjudicación.

- Todo el personal deberá disponer de identificaciones reconocibles y uniformes con los logos de la empresa durante la ejecución de las actividades descritas en el contrato.

Y, por último, como medidas para el seguimiento y control:

- Inspecciones periódicas a la empresa para evaluar la implementación de las políticas internas de la organización, personal y equipos.

- Reuniones con las comunidades locales próximas a las cadenas de suministro para conocer el impacto de las operaciones de la empresa en sus fases de producción de los suministros y/o servicios.

- Realizar consultas a organizaciones especializadas (como centros de investigación, organizaciones de defensa de los derechos humanos y think tanks, entre otros) en el sector de la actividad externalizada.

Como se comprueba, las medidas propuestas guardan estrecha relación con las propuestas en la Guía del Ayuntamiento de Barcelona. Se trata en ambos casos de llevar a las diferentes fases de los procesos de contratación una serie de medidas que eviten contratar con empresas que vulneran los derechos humanos y que permitan también dejar sin efecto los contratos celebrados con empresas que, de forma directa o indirecta, a través de sus subcontratistas, vulneran los derechos humanos.

\section{CONCLUSIONES}

La contratación pública, que conlleva un elevadísimo volumen de gasto público, ha superado su concepción inicial como mecanismo para que las administraciones se proveyeran de bienes y servicios, para añadir a esos objetivos el logro de otros fines de interés general, en particular objetivos sociales y medioambientales. Es lo que se ha dado en llamar la función estratégica de la contratación. En los últimos años a estos fines complementarios se ha añadido la defensa de los derechos humanos. Si los derechos humanos son el fundamento 
de la vida social, parece obvio que la contratación pública, que es una potestad pública, no puede desconocer su significado y debe ponerse al servicio de su promoción y defensa. Para ello, es esencial garantizar que la Administración contrata con empresas que respetan los derechos humanos, y promocionar a aquellas que son más respetuosas con los mismos. Desde este planteamiento importa conocer cuál es el contenido de los derechos humanos reconocidos en cada ordenamiento para, a continuación, vincular la regulación y ejercicio de la contratación pública con su protección y desarrollo. No pueden obviarse los fines institucionales de la contratación pública, en particular asegurar procesos selectivos basados en la publicidad y concurrencia, pero sí que pueden introducirse en las diversas fases de la contratación medidas que tengan como finalidad asegurar que las empresas contratistas respeten los derechos humanos. En este trabajo se da cuenta de dos experiencias concretas que ilustran cómo pueden introducirse mecanismos concretos en las fases de preparación, adjudicación, ejecución y supervisión de la contratación con este fin.

\section{BIBLIOGRAFÍA}

Acuña, Fernando. "Las graves vulneraciones de Derechos Humanos como prohibiciones de contratar". Observatorio de Contratación Pública, 13 de septiembre de 2017. Disponible en línea: http://www.obcp.es/opiniones/las-graves-vulneraciones-dederechos-humanos-como-prohibicion-de-contratar

Bernal Blay, Miguel Ángel. "Hacia una contratación pública socialmente responsable: las oportunidades de la Ley 30/2007 de 30 de octubre de contratos del sector público". En José María Gimeno Feliu (ed.), El derecho de los contratos del Sector Público, Monografías de la Revista Aragonesa de Derecho Público, n. ${ }^{\circ}$ X. Zaragoza: 2008.

Burzaco, María. "Contrataciones públicas socialmente responsables: la Necesidad de reconsiderar el potencial de la contratación pública en la consecución de Objetivos sociales". A CIRIEC - Revista de Economía Pública, Social y Cooperativa, n. ${ }^{\circ} 86$, 2016, pp. 281-310.

Camós, Margarida y María Teresa Vadrí. La posible inclusión de Criterios de paz y de derechos bumanos en la contratación pública. Materiales de Paz y Derechos Humanos. Barcelona: Oficina de Promoción de la Paz y de los Derechos Humanos de la Generalidad de Cataluña, 2010.

Gallego CórColes, Isabel. "Cláusulas sociales, contratación pública y jurisprudencia del TJuE". Contratación Administración Práctica, n. ${ }^{\circ}$ 113, 2011.

Gallego Córcoles, Isabel. "Las cláusulas sociales como criterio de adjudicación". Contratación Administrativa Práctica, n. ${ }^{\circ}$ 152, 2017. 
Gallego Córcoles, Isabel. "La integración de cláusulas sociales, ambientales y de innovación en la contratación pública". Documentación Administrativa, nueva época, n. ${ }^{\circ} 4$, enero-diciembre de 2017.

Gimeno Feliu, José María. El nuevo paquete legislativo comunitario sobre contratación pública. De la burocracia a la estrategia. El contrato público como berramienta del liderazgo institucional de los poderes públicos. Cizur Menor: Thomson - Aranzadi, 2014.

Gimeno Feliu, José María. "Las condiciones sociales en la contratación pública: posibilidades y límites". Anuario de Gobierno Local, n. ${ }^{\circ}$ 1, 2017.

Gosálbez Pequeño, Humberto. “¿Cláusulas sociales en la selección de los contratistas de las administraciones públicas españoles?". Justicia Administrativa, n. . 20, 2003, pp. 27-67.

Lesmes Zabalegui, Santiago y Leire Álvarez de Eulate. Guía de contratación pública socialmente responsable. Bilbao: REAs Euskadi, 2014.

Llop, PILAR. "Derechos humanos y contratación pública", Confilegal, 6 de octubre de 2015. Disponible en línea: https://confilegal.com/20151006-derechos-humanosy-contratacion-publica/.

Martín Ortega, Olga y Opi Outwhite. "Empresas, derechos humanos y contratación". En Víctor Messeguer Sánchez (dir.), Empresas, derechos bumanos y RSC. Cizur Menor: Thomson Reuters, 2016.

MARTínez FernándeZ, José MaríA. "Avanzando en contratación socialmente responsable: de la recomendación a la obligaciones". A Observatorio de Contratación Pública, 2015.

Medina Arnáiz, Teresa. "La contratación pública socialmente responsable a través de la jurisprudencia del TJUE". REDA, n. ${ }^{\circ} 153,2012$, pp. 1-20.

Medina Arnáiz, Teresa. "El destino de las cláusulas sociales en la contratación pública". En José María Gimeno Feliu (dir.), Observatorio de los contratos públicos. Cizur Menor: Thomson-Aranzadi, 2019.

Oficina del Alto Comisionado de Naciones Unidas para los Derechos Humanos. Cuarta Consulta Regional sobre empresas y derechos humanos para América Latina y el Caribe. Santiago de Chile, CEPAL, 3 y 4 de septiembre de 2019.

Pernas García, Juan José (coord.). Contratación pública estratégica. Cizur Menor: Aranzadi, 2013.

Pleite Guadamillas, Francisco. "Incorporación de cláusulas de contenido social, laboral y medio ambiental en los Pliegos que rigen las licitaciones de los Contratos". A Contratación Administrativa Práctica, n. 138, 2015. 
Ramírez Hortelano, Patricia. "Las cláusulas sociales en la contratación administrativa". Contratación Administrativa Práctica, n. ${ }^{\circ}$ 42, 2005.

Tornos, Joaquín, Agustí Fernández de Losada, Anna Calvete y Juan Ambrós. Guía para la protección y la promoción de los derechos bumanos en la contratación pública. Barcelona: Creative Commons, 2017.

Tudor, Elena Cristina. "La contratación pública y la formación de los derechos humanos". Revista de Pensamiento Jurídico, vol. 10, n. ${ }^{\circ}$ 2, 2016.

ZúÑIGa Rial, GLORIA. "El tratamiento de las cláusulas sociales en la normativa reguladora de la contratación pública. Su consideración como criterios de adjudicación de los contratos administrativos". Direitto, vol. 17, n. ${ }^{\circ}$ 2, 2008, pp. 65-90. 